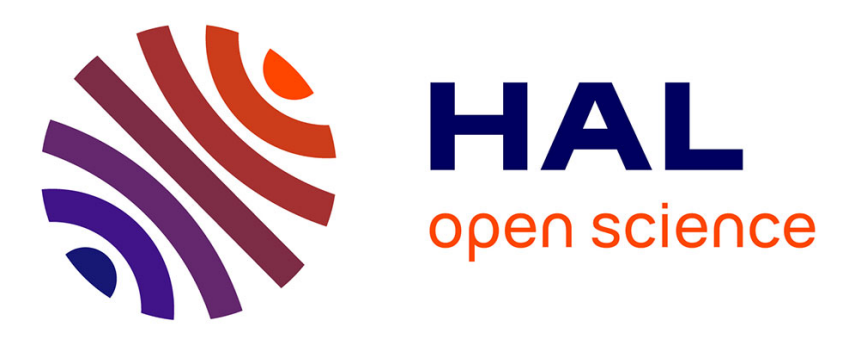

\title{
Sensitivity experiments on True Polar Wander
} Marianne Greff-Lefftz, Jean Besse

\section{To cite this version:}

Marianne Greff-Lefftz, Jean Besse. Sensitivity experiments on True Polar Wander. Geochemistry, Geophysics, Geosystems, 2014, 15, pp.4599-4616. 10.1002/2014GC005504 . insu-03581056

\section{HAL Id: insu-03581056 https://hal-insu.archives-ouvertes.fr/insu-03581056}

Submitted on 19 Feb 2022

HAL is a multi-disciplinary open access archive for the deposit and dissemination of scientific research documents, whether they are published or not. The documents may come from teaching and research institutions in France or abroad, or from public or private research centers.
L'archive ouverte pluridisciplinaire HAL, est destinée au dépôt et à la diffusion de documents scientifiques de niveau recherche, publiés ou non, émanant des établissements d'enseignement et de recherche français ou étrangers, des laboratoires publics ou privés.

$$
\text { Copyright }
$$




\section{Geochemistry, Geophysics, Geosystems}

\section{RESEARCH ARTICLE Sensitivity experiments on True Polar Wander}

\subsection{2/2014GC005504}

Key Points:

- Principal Inertia Axes and TPW

- TPW during the formation and the

destruction of a supercontinent

-TPW leads to a successive equatorial or polar distribution of continents

\section{Correspondence to:}

M. Greff-Lefftz,

greff@ipgp.fr

Citation:

Greff-Lefftz, M., and J. Besse (2014), Sensitivity experiments on True Polar Wander, Geochem. Geophys. Geosyst., 15, 4599-4616, doi:10.1002/

2014GC005504.

Received 17 JUL 2014

Accepted 10 NOV 2014

Accepted article online 17 NOV 2014

Published online 1 DEC 2014

\author{
Marianne Greff-Lefftz ${ }^{1}$ and Jean Besse ${ }^{1}$ \\ ${ }^{1}$ Institut de physique du globe de Paris-Sorbonne Paris Cité, Université Paris Diderot, UMR CNRS 7154, Paris, France
}

\begin{abstract}
Using sensitivity experiments based on the position of subductions and of superplumes, we derive models for the temporal evolution of 3-D mass anomalies in the mantle and compute the associated inertia perturbations and polar wander. We show that although the large length-scale mantle dynamics during the Earth's history may have been dominated by coupled supercontinent-superplume cycles, subductions alone are sufficient to trigger major True Polar Wander (TPW) episodes, or rotation of the whole lithosphere and mantle with respect to the Earth's rotation axis. We present two examples. We speculate that the distribution of continents with respect to the equator on the Earth's surface is driven by episodic subductions during the Wilson cycle: alternating fast subduction girdles around continents and upwellings during the divergence phases, with both reduced or stopped subductions activity around continents and moderate inter-continental subductions during the convergence phases, lead to successive equatorial or polar distributions of continents, both configurations being separated by strong episodes of TPW. Finally, using plate reconstructions and geologic maps, over the period 1100-720 Ma, the period of amalgamation and destruction of the Rodinia supercontinent, we explain with our model the observed large eastward/ westward and poleward/equatorward motions of the rotation axis.
\end{abstract}

\section{Introduction}

The Earth's history is possibly dominated by a supercontinent cycle, with an episodic aggregation and dispersal of Earth's continental crust accompanied by superplume events (for a review see Li and Zhong, [2009] and Yoshida and Santosh [2011]). During this cycle, major true polar wander events (TPW) may occur (in this study, True Polar Wander will refer to the large-scale motions of the Earth's rotation axis with respect to a fixed terrestrial frame). On geological time scales, this motion is linked to modes of mantle convection [Gold, 1955; Goldreich and Toomre, 1969; Steinberger and O'Connell, 1997; Zhong et al., 2007; Steinberger and Torsvik, 2010], and hence to the temporal variation of the mantle density heterogeneities. Recurrent explanations refer to inertial perturbations linked to domes--the two large-scale upwellings (thermo-chemical piles) at the bottom of the lower mantle--and episodic ascent of hot (less dense) material in the mantle [Evans, 2003] and/or to the inertial perturbations associated with subducted plates [Richards et al., 1997; Rouby et al., 2010; Greff-Lefftz and Besse, 2012].

A ring of subduction zones (such as the present Ring of Fire) has probably existed around the envelope of continents [Evans, 1998; Collins, 2003], delimitating a huge oceanic domain (at present the Pacific Ocean, or during Pangea times the Panthalassa) opposed to a domain containing continents (or episodically supercontinents). These subduction zones have a considerable impact on mantle dynamics as they lead to a subcontinent return flow responsible for the formation of one or two antipodal superplumes, causing for instance the breakup of supercontinents. Such a ring of subductions probably exists during long periods of times, but the subduction rate, on a location, may vary, as shown by the analysis of calc-alkaline volcanism along the western margin of North America [Greff-Lefftz and Besse, 2012]. Another feature is the existence of a roughly E-W striking ocean such as the Indian Ocean at present, the successive Tethyan domains during Late Paleozoic and Mesozoic, or the Rheic Ocean during early Paleozoic. These ocean domains result from the rifting of continental blocks from the South continent leading to a South verging E-W subduction zone, which stops after the collision against the northern continent. After a while, a new subduction rebirths nearby the previous collision [Collins, 2003].

In this paper, we try to separate the respective role of domes and subduction types on TPW. We use a simple model which describes the large-scale pattern of mantle dynamics, and investigates how subducted 

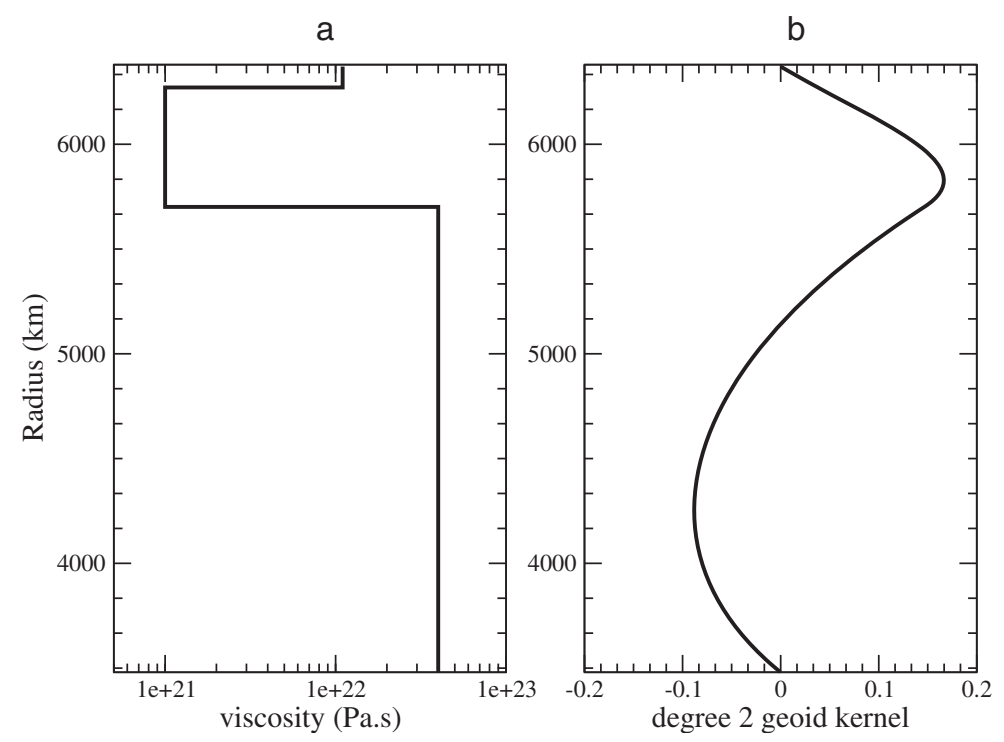

Figure 1. (a) Viscosity profile within the mantle as a function of the radius. (b) Degree 2 geoid kernel as a function of the radius.

lithosphere and long wavelength upwellings perturb the mantle density heterogeneities and create a drift of the rotational axis with respect to a fixed terrestrial reference frame. The article is organized as follows. In section 2, we detail our geodynamical model and present some simple examples. In section 3, we propose an explanation for the observed TPW during the assembly and the destruction of the Pangea, which is characterized by successive tracks separated by abrupt cusps. In section 4, we use published paleogeographic evolution of the supercontinent Rodinia from its aggregation to its dispersal [ $L i$ et al., 2008, 2013] to speculate how changes in subductions distribution and velocities have trigger True Polar Wander. Finally we discuss our results and conclude.

\section{Geodynamical Model}

We first present our simple model for the large-scale pattern of mantle dynamics. We combine contributions due to subducted lithosphere and to long wavelength upwellings. In this geodynamic model, the mantle is assumed to be homogeneous in density; the lithosphere, the upper and the lower mantles are viscous with respective viscosity plotted in Figure 1a; the core is a homogeneous inviscid fluid.

\subsection{Downwelling Model}

We start with the model of mantle density heterogeneity derived by [Ricard et al., 1993a]. They used platemotion reconstructions under the assumption that subducted slabs sink vertically into the mantle [see Lithgow-Bertelloni and Richards, 1998, Figure 5]. The velocity of the vertically sinking slabs depends on the position of the slabs within the mantle and on the viscosity ratio between lower and upper mantle: it is equal to the surface velocity of the plates $v_{s}$ when the sinking slabs are in the upper mantle, whereas it is equal the surface velocity of the plates divided by a factor $V_{R}$ when the slabs are in the lower mantle. The characteristic time $t_{C M B}$ needed for a plate to sink through the whole mantle consequently is:

$$
t_{C M B}=\frac{670 \times 10^{3}}{v_{s}}+v_{R} \frac{(5701-3480) \times 10^{3}}{v_{s}}
$$

where $v_{s}$ is in meter per year and $t_{C M B}$ in year. In our study, we have fixed the viscosity ratio between lower and upper mantle to 40 , and then, we have $V_{R}=4$. Consequently, if the surface velocity $v_{s}$ is about $7.5 \mathrm{~cm} /$ $y$, we will obtain $t_{C M B}=127$ Myrs.

The model assumes also that the size (the thickness) of the sinking slab is increased by the same factor $V_{R}$ in the lower mantle (Figure $2 b$ ). 
(a)

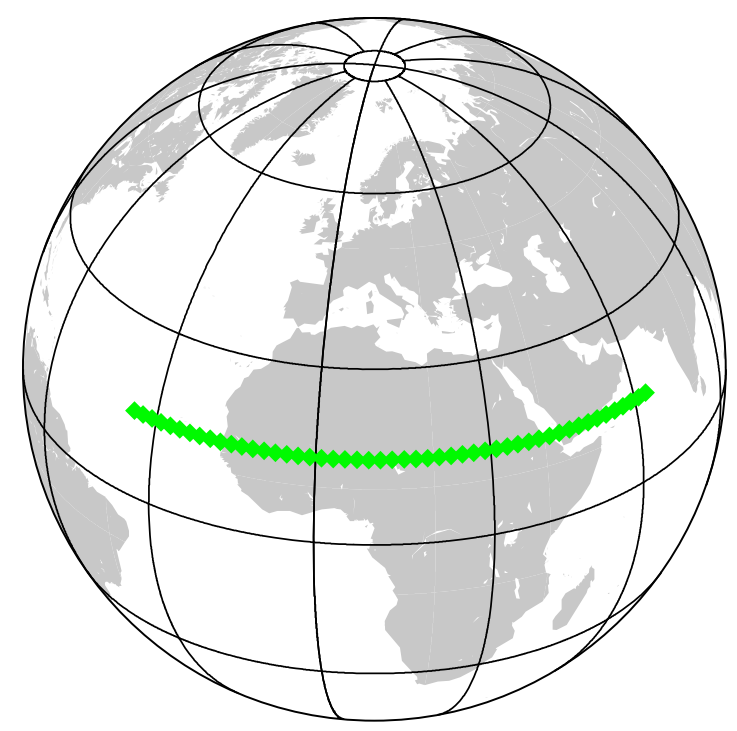

(b)

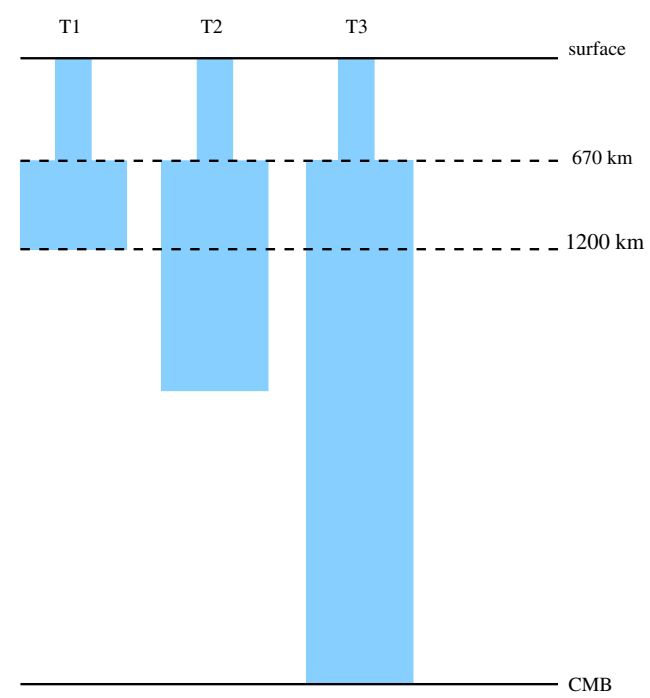

(c)

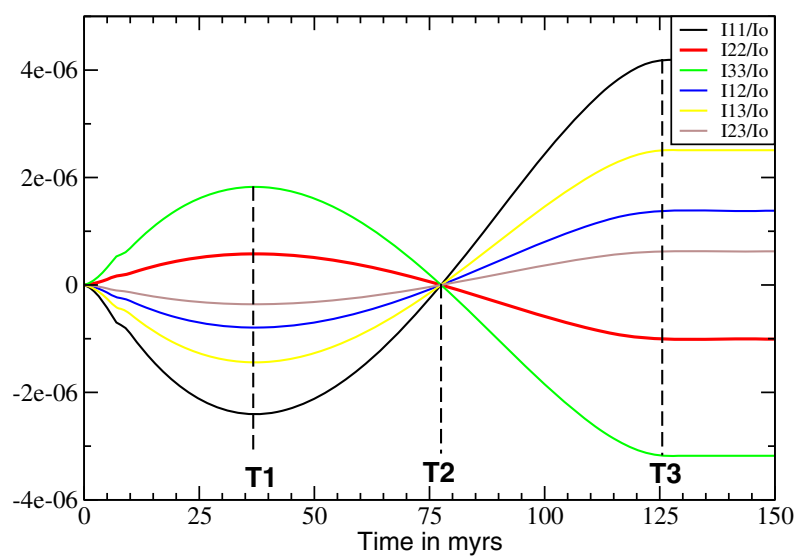

Figure 2. (a) Position of the subduction zone. (b) Mantle density heterogeneities induced by sinking plates for different times $T_{1}, T_{2}$ and $T_{3}$. The depth and the plotted interfaces are labeled on the right. (c) Temporal evolution of the perturbations of the six components of the inertia tensor.
Because the mantle is not rigid, these mass anomalies involve internal mass redistributions and associated surface readjustments that have to be taken into account in the computation of the geoid--the gravitational equipotential at the Earth's surface--in addition to the direct effect of the mass [Richards and Hager, 1984]. In a reference frame centered at the Earth's center of mass $O$, this geoid is expanded in spherical harmonics:

$$
\begin{aligned}
\operatorname{Geoid}(\theta, \varphi) & =a \sum_{n=2}^{n \max } \sum_{m=0}^{n}\left(c_{n m} \cos m \varphi\right. \\
& \left.+s_{n m} \sin m \varphi\right) P_{n}^{m}(\cos \theta)
\end{aligned}
$$

where $a$ is the Earth's radius, $P_{n}^{m}$ the Legendre functions, $\theta$ the colatitude and $\varphi$ the longitude. $c_{n m}$ and $s_{n m}$ are the coefficients of the spherical harmonics expansion, normalized to $4 \pi$. To compute these coefficients, we use a "degree $n$ geoid kernel," that is to say a transfer function between the degree $n$ coefficients of the spherical harmonics expansion of the mantle mass anomaly and the ones of the geoid $c_{n m}$ and $s_{n m}$ [Richards and Hager, 1984].

By MacCullagh's theorem [e.g., Munk and MacDonald, 1960], we may relate the components of the inertia tensor perturbation induced by the mantle mass anomalies $\left(l_{i j}\right.$ for $\left.i, j=1 . .3\right)$ to the degree 2 spherical harmonics coefficients of the geoid:

$$
\begin{aligned}
& \frac{l_{i j}}{I_{0}}= \\
& \frac{M a^{2}}{I_{0}}\left(\begin{array}{ccc}
\frac{c_{20}}{\sqrt{3}}-c_{22} & -s_{22} & -c_{21} \\
-s_{22} & \frac{c_{20}}{\sqrt{3}}+c_{22} & -s_{21} \\
-c_{21} & -s_{21} & -2 \frac{c_{20}}{\sqrt{3}}
\end{array}\right)
\end{aligned}
$$

where $I_{o}$ is the inertia tensor of a spherical nonrotating Earth with a mass $M$ : $\left(I_{o}=0.33 \mathrm{Ma}^{2}\right)$. We do not take into account the diagonal inertia tensor perturbation 
induced by the degree zero mantle mass anomalies, since such a perturbation will only cause variations in the length of day but no change in the TPW [Greff-Lefftz, 2011]. Consequently to compute the inertia perturbations induced by the mantle mass anomalies taking into account the viscous gravitational deformations, we use a "degree 2 geoid kernel": this function is plotted (Figure 1b) for our reference Earth's model using a viscosity profile (Figure 1a) with $V_{R}=4$. The geometrical and physical parameters of the four-layered reference Earth model are given in Rouby et al. [2010, Table 1]. A particular characteristic of this kernel is that a positive mass anomaly located in the upper part of the mantle (depth less than $1200 \mathrm{~km}$ ) will involve a positive geoid whereas a positive mass anomaly in the lower mantle (depth larger than $1200 \mathrm{~km}$ ) will involve a negative geoid.

\subsubsection{Example 1: A Single Plate Subduction}

We first study the effect of one slab sinking vertically within the mantle. This situation corresponds for example to the effect of Tethyan subductions. At $t=0$, the plate starts to sink at the surface velocity of $7.5 \mathrm{~cm} / \mathrm{yr}$ along a subduction zone plotted in green on Figure 2a. We compute and plot the temporal evolution of the 6 components of the inertia tensor perturbation normalized to the inertia tensor of a spherical nonrotating Earth (Figure 2c). For $t<T_{1}$, the masses are located at depth smaller than $1200 \mathrm{~km}$ (Figure 2b) and involve positive degree 2 geoid. For $t=T_{2}$ the perturbations of the degree 2 geoid induced by the masses located beneath $1200 \mathrm{~km}$ exactly compensate the perturbations induced by masses above $1200 \mathrm{~km}$ and consequently the six components of the inertia tensor are zero. For $t>T_{2}$, most of the masses are in the lower mantle and the associated degree 2 geoid perturbation is negative, whereas for $t=T_{3}$ the slab reaches the CMB where it is isostatically compensated.

We diagonalize the inertia tensor perturbations to compute the temporal evolution of the Principal Inertia Axis (PIA). We find that for $t<T_{2}$ Myrs, the minimum PIA will be the axis passing through the center of mass of the Earth $O$ and the center of mass of the plate, whereas this axis will become the maximum PIA for $t>T_{2}$ : there is thus an inertial interchange at $t=T_{2}$. For a surface velocity of $7.5 \mathrm{~cm} / \mathrm{yr}$, we have $T_{2} \simeq 75$ Myrs.

\subsubsection{Example 2: A Girdle of Subductions}

We now assume a girdle of subductions around a supercontinent (located on a small circle of the sphere centered at $\left[0^{\circ}, 0^{\circ}\right]$ with a radius about $80^{\circ}$ (black circle on Figures 3 a and $3 \mathrm{~b}$ ) with a constant surface velocity about $7.5 \mathrm{~cm} / \mathrm{yr}$ which starts to sink into the mantle at $t=0$. Similarly to the previous example, for $t<T_{2}$ the subducted masses are in the upper part of the mantle and consequently induce a hole in the degree 2 geoid centered on the center of the small circle $\left[0^{\circ}, 0^{\circ}\right.$ (Figure 3a), whereas for $t>T_{2}$ most of the cold masses are in the lower mantle and thus induce a high in the degree 2 geoid at $\left[0^{\circ}, 0^{\circ}\right]$ (Figure $3 \mathrm{~b}$ ). The temporal evolution of the perturbations of the moments of inertia is plotted on Figure $3 c$. We show that for $t<T_{2}$, the maximum PIA is the axis passing through the Earth's center of mass $O$ and the center of the small circle $\left(\left[0^{\circ}, 0^{\circ}\right]\right.$ in this example), whereas for $t>T_{2}$ the minimum PIA coincides with this axis and the two maximum PIA are in a perpendicular plane: at $t=T_{2}$ there is an inertial interchange.

Note that, because of the large amount of subducted cold materials, the amplitude of the perturbations of the inertia tensor is larger for a girdle of subduction than for a Tethyan-like subduction, by about a factor 3 , and thus the subduction at the periphery of continents will be the dominant source of perturbations of the PIA due to subducted plates.

In this example, we assumed that the size (the thickness) of the sinking slab was increased by a factor $V_{R}=4$ in the lower mantle, that is to say that large sheets of cold material were sinking down to the lower mantle. To fix a lower bound for the effect of a girdle of subduction on the inertia of the Earth, we put $V_{R}=1$ in our computation: in this extreme case, we find that the sinking slab will reach the CMB in less than 40 My and the amplitudes of the inertia tensors perturbations will be decreased by a factor 2 .

\subsection{Upwelling Model}

Seismic tomography models show two present-day large-scale zones at the CMB in which wave velocities are abnormally slow: the Large-Low Shear Wave Velocities Provinces (LLSVPs) [Dziewonski, 1984]. They are sometimes interpreted as two thermo-chemical domes that are chemically denser than the overlying mantle [McNamara and Zhong, 2005], explaining their stability over long periods of time. They are probably overlain by hot and less dense large-scale upwellings or plumes in the ambient mantle, which may dominate the effect on the geoid [Steinberger and Torsvik, 2012]. As a consequence, the "domes" are associated 
(a) $\mathbf{t}=\mathbf{T} \mathbf{1}$
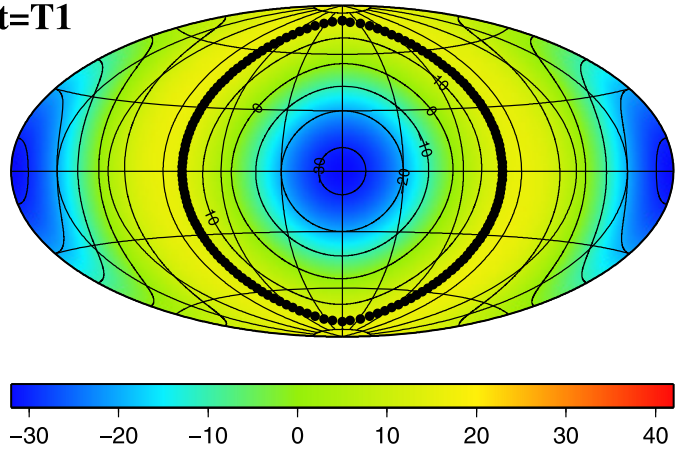

Degree 2 geoid (meter)

(b) $\mathbf{t}=\mathbf{T} 3$
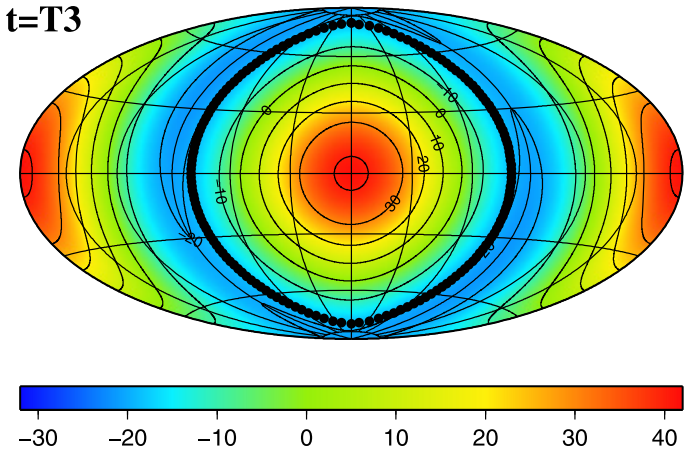

Degree 2 geoid (meter)

(c)

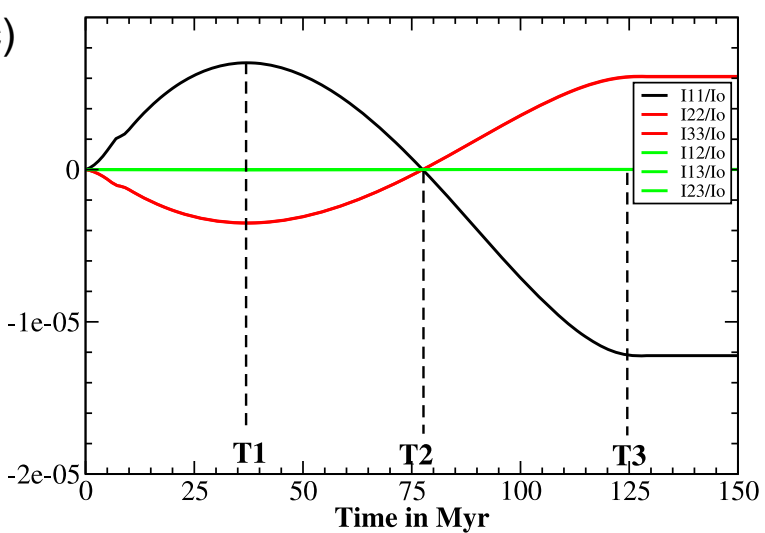

Figure 3. (a) Degree 2 geoid for $t=T_{1}$. Black small circle: girdle of subduction. (b) Degree 2 geoid for $t=T_{3}$. (c) Temporal evolution of the perturbations of the moments of inertia. with geoid highs, even though the domes themselves are positive density anomalies, and would account for the existence of the superswells observed at the Earth's surface, one beneath Africa and the other one in the Pacific. According to Zhong et al. [2007], mobile-lid mantle convection in a three-dimensional spherical shell is characterized by a spherical harmonic degree-1 planform with a major upwelling during the assembly of the supercontinent, changed to two major antipodal upwellings during the supercontinent stage. The axis of the mantle upwelling is complementary to the cold downwelling girdle of subduction encircling the supercontinent, which forces the hot lower mantle to rise.

To model the distribution of mantle mass anomalies associated with domes, we extend a simple modeling derived from Greff-Lefftz and Besse [2012]: domes are modeled as one or two partially full hemispheres (Figure 4a) with a radius $\alpha=45^{\circ}$ and a height $h=600 \mathrm{~km}$ aligned with an axis passing through the center of the supercontinent. Because the present-day domes are associated with geoid highs, we arbitrarily fixed to -50 $\mathrm{kg} / \mathrm{m}^{3}$ their density contrast with respect to the surrounding mantle, although these densities are still debated.

Such a dome involves not only a large degree 1 coefficient in the spherical harmonics expansion of the mantle mass anomaly but also, because of its hemispheric geometric form, some degree 2. In our model, the mass anomaly of one dome is about -3.3

$\times 10^{20} \mathrm{~kg}$, negligible in comparison with the Earth's mass. We can compute the inertia perturbation associated with this mass anomaly without taking into account the shifting (which is less than $200 \mathrm{~m}$ ) of the centre of mass of the system. The associated inertia tensor perturbations, for a unique dome located at the equator on an axis passing through the center of the supercontinent and its antipode, is then computed using the degree 2 geoid kernel plotted on Figure $1 \mathrm{~b}$ :

$$
\frac{I_{i j}^{D}}{I_{o}}=\left(\begin{array}{ccc}
-0.5 \times 10^{-5} & 0 & 0 \\
0 & 0.25 \times 10^{-5} & 0 \\
0 & 0 & 0.25 \times 10^{-5}
\end{array}\right)
$$


(a)

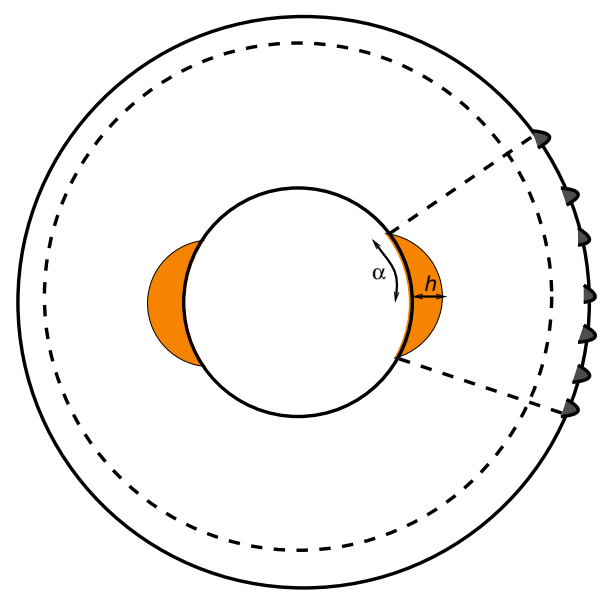

(b)
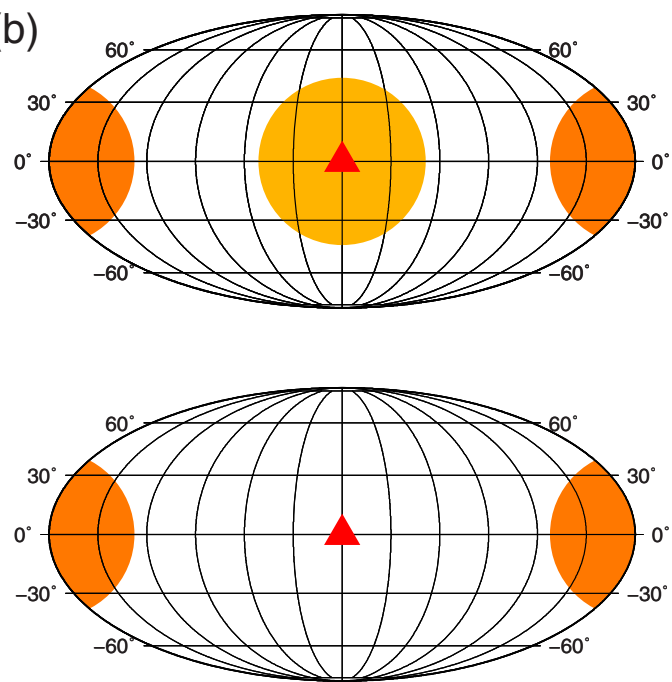

Figure 4. (a) Schematic for domes at the bottom of the mantle and the surface intraplate volcanism above it. The angle $\alpha$ is the radius of the dome and $h$ its height. (b) One or two full domes aligned with an axis passing through the center of the supercontinent (red triangle), the origin of our fixed reference frame.

If we take into account two antipodal domes, because of the geometry of our system, the degree one coefficient of the associated mass anomalies will vanish and the amplitude of the inertia perturbations will be simply doubled.

Individual plumes coming from the margins of the domes, as well as primary plumes coming from the lower most mantle boundary layer will create mantle mass anomalies with smaller wavelengths and consequently will induce only smaller perturbations of the inertia tensor, related to degree 2 density heterogeneities. To quantify them, we have used the simple model described in Greff-Lefftz [2004], for a hot spherical plume (with a radius about $300 \mathrm{~km}$ and a density contrast of $-50 \mathrm{~kg} / \mathrm{m}^{3}$ ) crossing the mantle at the Stoke's velocity: we have obtained maximal perturbations of the inertia tensor of about $10^{-7} \times I_{0}$. The associated polar motion will be negligible or will appear as an excursion of fews degrees on a trajectory of the pole governed by the subducted plates and by the domes.

Comparing the amplitude of the inertia tensor perturbations induced by the downwellings $\left(V_{R}=4\right)$ with the ones induced by two stable domes at the bottom of the mantle, we find that the effect of domes would probably be at least as large as the effect of slabs. The precise amount of cold slabs in the lower mantle is still uncertain but a factor $V_{R}=4$ seems to be in good agreement with what is currently observed at present by seismic tomography.

\subsection{Polar Motion}

The temporal evolution of the Earth's rotational vector can be deduced from the inertia tensor perturbations, by solving the equations governing the conservation of the angular momentum of the Earth $\vec{H}$ [Munk and MacDonald, 1960], in a frame corotating with the mantle:

$$
\frac{d \vec{H}}{d t}+\vec{\omega} \wedge \vec{H}=\vec{O}
$$

where $\vec{H}=J . \vec{\omega} . J$ is the inertia tensor of the Earth and $\vec{\omega}$ is the angular velocity of the reference frame. The time-dependent inertia tensor $\mathbf{J}(t)$ may be written as the sum of 3 parts:

$$
J_{i j}=I_{o} \delta_{i j}+C_{i j}+I_{i j}
$$

where $\delta_{i j}$ is the Kronecker symbol. The first term $I_{o}$ is the inertia tensor of the reference spherical nonrotating Earth. The second term $C_{i j}$ is the inertia perturbation associated with the response of the Earth to the changing centrifugal potential, and consequently depends on the components of the rotation vector; the difference between the associated principal moments of inertia represents the rotational "bulge." The last 
term $l_{i j}$ describes changes in inertia due to mantle mass anomalies, including internal mass redistributions and the associated surface readjustments as described in the previous section.

The geological time is large in comparison with the length of day and consequently $\frac{d}{d t} \ll \omega$, and the equation governing the polar wander may be written:

$$
\vec{\omega} \wedge \vec{H}=\vec{O}
$$

or, in the quasi-fluid approximation [Ricard et al., 1993b], using indicial notation:

$$
\epsilon_{i j k} \omega_{j} \dot{\omega}_{k}=\epsilon_{i j k} \frac{I_{k l}}{\alpha l_{o} T_{R}} \omega_{l} \omega_{j}
$$

where $\alpha$ is the hydrostatic flattening of the Earth (difference between polar and equatorial inertia moments of the hydrostatic rotational bulge divided by the equatorial moment: $\alpha=\frac{1}{305}$ ) and $T_{R}$ the characteristic time of the delayed readjustment of the equatorial bulge of a rotating planet toward this fluid position. $T_{R}$ may be computed with the use of the tidal viscoelastic Love number [Ricard et al., 1993b]. For our mantle model of viscosity, its value is about $20 \mathrm{kyr}$ [Greff-Lefftz, 2011]. The time scale at which the rotation axis will adjust to the maximum principal inertia axis depends consequently on two terms: the relaxation of the rotational bulge $\left(\alpha I_{0} T_{R}\right)$, and the amplitude and the temporal evolution of the inertia tensor perturbations induced by internal loads $\left(I_{k}\right)$. For our mantle density heterogeneities model, the difference between the inertia moments of mantle convection varies between $1-2 \times 10^{-5} I_{o}$, and consequently, the time scale at which the rotation axis will adjust to the maximum principal inertia axis will be a few millions years [Tsai and Stevenson, 2007; Cambiotti et al., 2011; Chan et al., 2011].

Let us now present some simple examples combining downwellings and domes in the mantle.

\subsubsection{Example 1: A Single Plate Subduction and One or Two Domes}

We simply add the perturbations of the inertia tensor induced by a single plate sinking vertically within the mantle (Figure $2 \mathrm{c}$ ) to the perturbations induced by one or two stable equatorial domes at the bottom of the mantle $\left(I_{i j}^{D}\right.$ or $\left.2 \times I_{i j}^{D}\right)$, at the position $\left[0^{\circ}, 0^{\circ}\right]$ and $\left[0^{\circ}, 180^{\circ}\right]$. This case may mimic the subduction effect corresponding to a convergence phase during the assembly of a supercontinent. The pole is assumed to be at North pole at time $t=0$, when the plate starts to sink into the mantle. The polar motion (i.e., the intersection of the rotational axis and the surface of the Earth) is plotted in Figure $5 \mathrm{a}$ as a black line with a single dome, a cyan line with two domes and a red line without dome at all. The amplitude of the inertia tensors perturbations when the slab is in the upper part of the mantle is small and consequently the velocity of the polar motion will be also small: the rotational bulge will tend to inhibit the motion of the rotational axis toward the maximum PIA. The pole first moves toward an antipodal position with respect to the plate, and then for $t>T_{2}$ (time when the amount of slabs below $1200 \mathrm{~km}$ exactly compensate the amount of slabs above $1200 \mathrm{~km}$ ), most of the masses being in the lower mantle, it changes its motion which becomes plateward (in fact toward the maximum PIA associated with the plate alone or with plates plus domes, according to the investigated cases). The temporal evolution of the latitude, longitude and velocity of the pole are plotted in the center part of the figure. We find that the domes tend to stabilize the pole in a plane perpendicular to its equatorial axis, that-is-to-say privilege a rotation pole on a great circle perpendicular to the minimum PIA of the inertia tensor due to domes. The limit value $\left(t>T_{3}\right)$ of the longitude of the rotation pole corresponds to a meridian located between $14^{\circ}$, the maximum PIA for the plate, and $90^{\circ}$ the maximum PIA for the domes: meridian $52^{\circ}$ if we take into account one dome and meridian $77^{\circ}$ with two domes (top of the right column of Figure $5 \mathrm{a}$ ). Note that the stabilizing effect of the domes leads also to a decrease of the velocity of the pole of rotation (bottom of the middle part of Figure $5 \mathrm{a}$ ).

\subsubsection{Example 2: A Girdle of Subduction and One or Two Domes}

We use the example described in section 2.1.2 and plot, in Figure 5b, the associated polar motion, assuming that the pole is at the North pole at time $t=0$ when the plate starts to sink into the mantle: for $t<T_{2}$, plates alone effect (red solid line) leads to a large motion toward the center of the girdle in more than 30 Myrs because of the small amplitude of the inertia perturbations. A quasi stable position of the rotational pole at the North pole is obtained when the effect of one (black line) or two (cyan line) domes are added to that of plates. For $t>T_{2}$, the rotational pole returns toward the North pole. The amplitudes of the inertia tensors perturbations induced by either one or two domes and the slab in the upper part of the mantle are 


\section{QAGU Geochemistry, Geophysics, Geosystems}

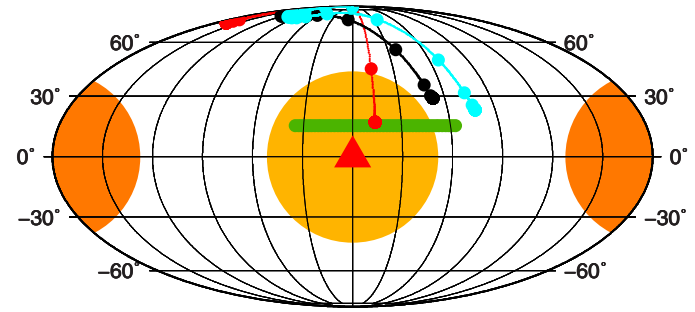

(a)
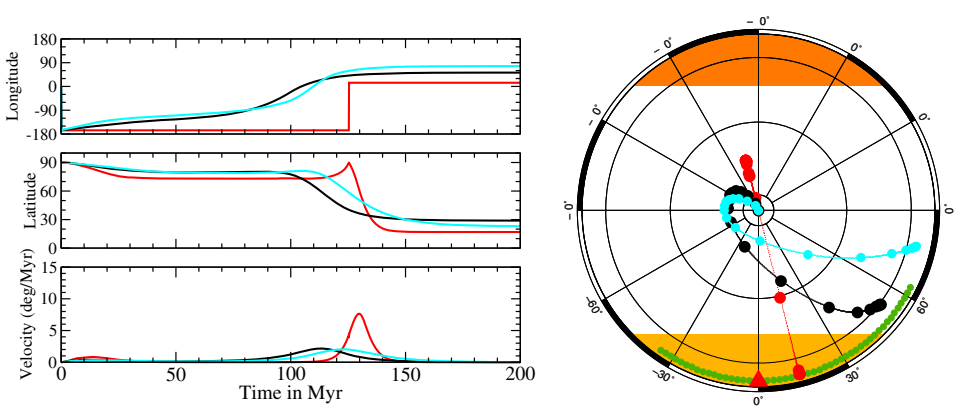

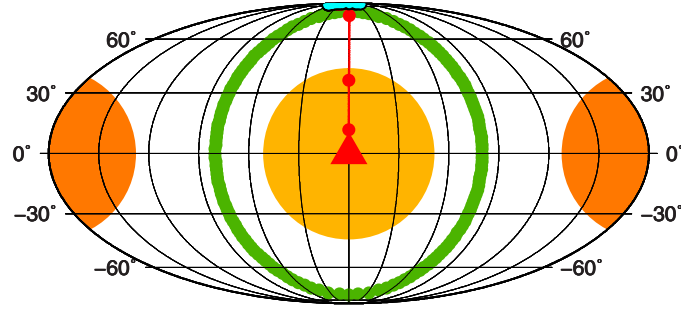

(b)
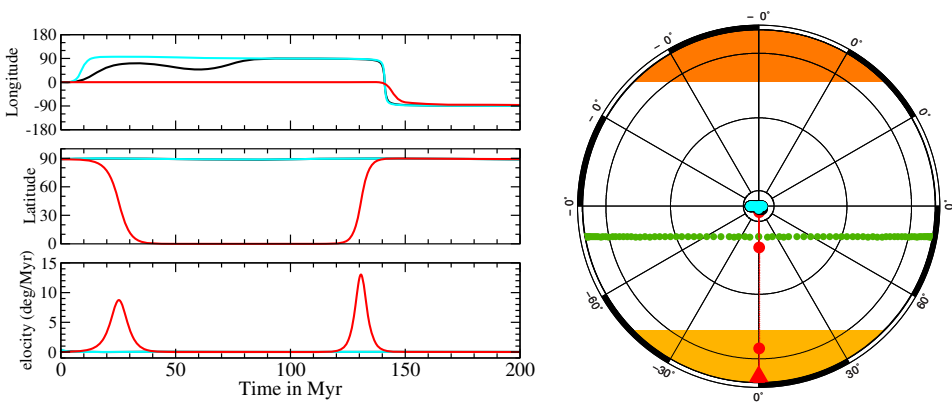

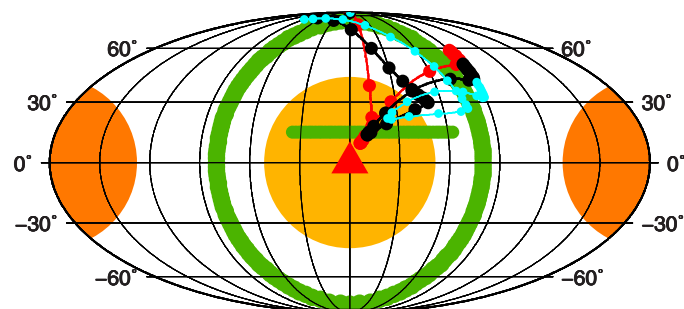

(c)
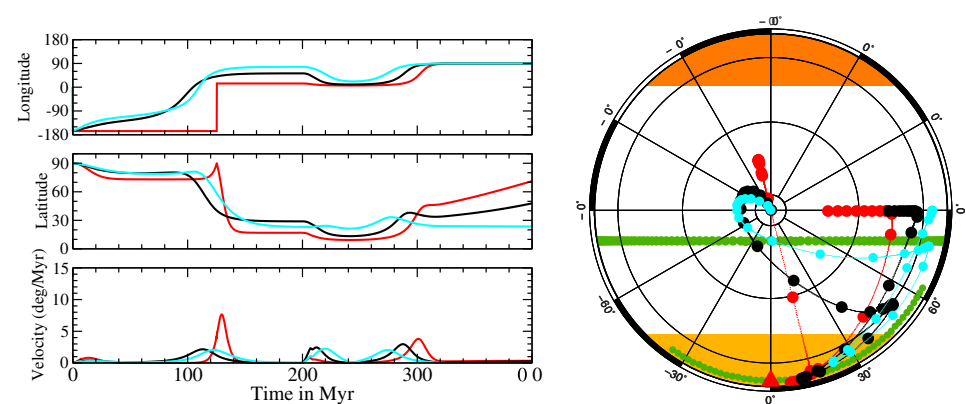

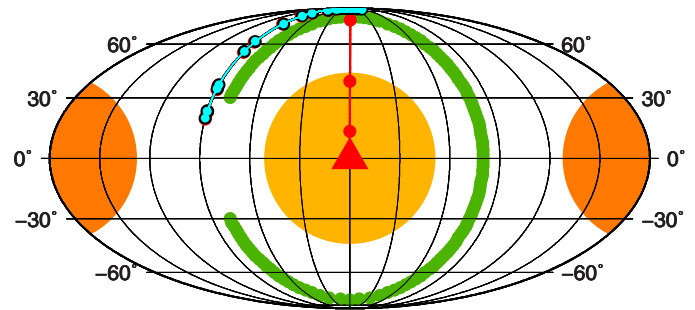

(d)
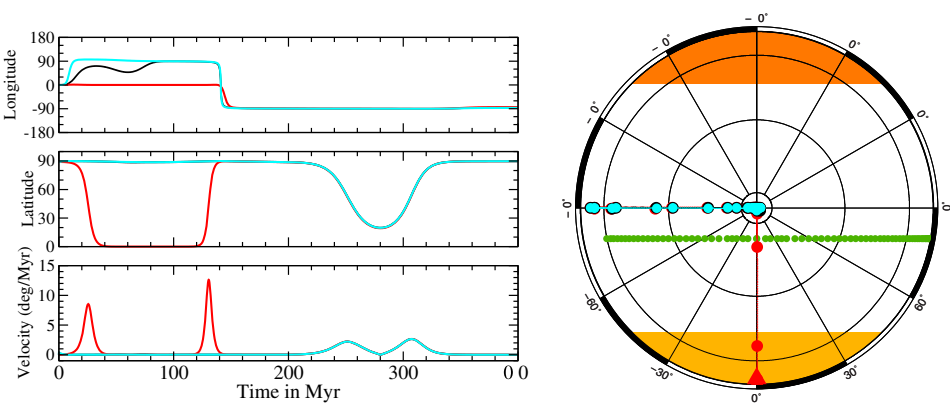

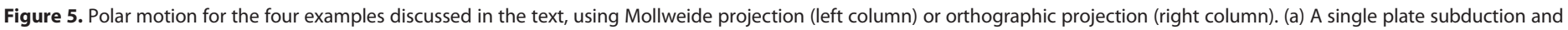
one or two domes, (b) a girdle of subduction and one or two domes, (c) a single plate followed by a girdle of subduction and one or two domes. (d) a girdle of subduction during 200 Myrs followed by a stop of a part of the subduction and one or two domes. The subductions are plotted as a thick green line and the domes as orange spherical caps. If we do not take into account the effects of the domes, the trajectory of the axis of rotation is plotted as red line; the polar motion is plotted as black line if we add one dome and in cyan if we add two

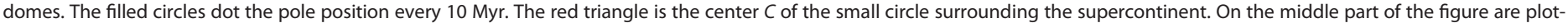
ted the temporal evolution of the latitude and of the longitude of the pole as well as its velocity in degree per Myr. 
very weak and have to be studied with scrutiny. If we add a single dome, there is not enough slabs in the upper mantle at the beginning. The dome dominates and consequently, the pole drift toward the meridian $90^{\circ}$. After a few Myrs, the effect of the slabs dominates and the pole tends toward the axis passing through the center of the girdle, this movement remaining close to the North pole. Then most of the plates are in the lowest part of the mantle and the pole remains stable at its initial position. If we add two domes, the effects of the domes are larger than the effects of the girdle of subduction.

Consequently, we show that the maximum PIA is mainly dominated by domes. It remains stable due to the symmetry of the dome and slab settings, as well as the choice of the initial position of the pole of rotation. Because of this weak amplitude of inertia perturbations, any other mass anomalies within the mantle involving perturbations of the inertia products breaking the symmetry of our plate will perturb the position of the pole.

\subsubsection{Example 3: A Single Plate Followed by a Girdle of Subduction and One or Two Domes}

We now combine the two previous examples to investigate the effect of a Tethyan-like subduction, from its initiation to its death, and the birth of a girdle of subduction: we assume that a single plate starts to sink into the mantle at $t=0$ and stops to dive at $t=200$ Myrs. Then, a girdle of subductions begins to sink from $t=200$ up to $t=400$ Myrs. This time scale is about 3 times $t_{C M B}$, the characteristic time needed for a plate to sink through the whole mantle; this choice is quite arbitrary and is motivated by the real case simulations done in section 4. We add one or two domes antipodal along an axis passing through the center of the girdle and the center of mass of the Earth. This situation would describe a convergence phase followed by a divergence phase during the assembly and dislocation of a supercontinent. The associated polar motion is plotted on Figure $5 c$, assuming that the pole is at the North pole at time $t=0$ when the plate starts to sink into the mantle, for the three cases--with one dome (black line), two domes (cyan line) or without dome (red line)--we find that the geometry of our system allows large motion of polar wander. At $t=200 \mathrm{Myr}$, the pole is at the final position of Figure $5 a$ (i.e., at the maximum PIA associated with the single plate alone or with domes). For $200<t<200+T_{2}$, the pole drift toward to new maximum PIA which is inside the ring of subduction, and finally for $t>200+T_{2}$, when most of the masses associated with the girdle of subductions are in the lower mantle, the pole returns toward the plane of the girdle.

This result shows that the effect of subductions are determinant for polar wander, and that the domes which involve a positive degree two geoid above the center of the supercontinents stabilize the minimum PIA in the equator plane. Such conclusion was also obtained by [Steinberger and Torsvik, 2010] which argue that LLSVPs stabilize the planet Earth and that TPW is caused by subduction.

\subsubsection{Example 4: A Girdle of Subducted Plates With Localized Interruption of Subduction} We now assume that a girdle of subduction starts to sink into the mantle at $t=0$ and that a part of this girdle stops to dive at $t=200$ Myrs. We add one or two domes antipodal along an axis passing through the center of the girdle and the center of mass of the Earth. This situation would describe some localized interruptions of subduction due to collisions between two continental plates. The polar motion associated with this configuration is plotted on Figure 5d. During the first 200 Myrs, we obtain the same results than in Figure $5 \mathrm{~b}$. At $t=200 \mathrm{Myrs}$, the pole is returned near the North pole. After 200 Myrs, the stop of the subduction perturbs the symmetry of our system and involves a large drift of the pole of rotation in a plane perpendicular to the center of the subduction girdle. During the first 75 Myrs, the mass mantle anomaly associated with the lack of subduction is in the upper part of the mantle and the pole drift toward the equator, whereas, for $t>275$ Myrs, the default of mass is in the lower mantle and the pole returns toward the North pole. Consequently, the end of the active subduction could be responsible for two tracks separated by an abrupt cusp at $t=275$ Myrs. Note that the cusp has occurred 75 Myr after the stop of the subduction, that is to say after a time delay equal to $T_{2}$, and that consequently the cusps in the observed TPW may result from earlier geodynamic events. For $t>200$ Myrs, the three curves (red, black and cyan) are identical because, the domes being aligned along an axis perpendicular to this plane, they do not perturb the trajectory of the pole.

In these different examples, the velocity of the polar wander may reach a value of 10 degrees per Myr ( $1 \mathrm{~m} /$ $\mathrm{yr}$ ), a large value in comparison with the velocity estimates for the last $200 \mathrm{Ma}$, where the faster TPW rate was about $3 \mathrm{~cm} / \mathrm{yr}$ [Besse and Courtillot, 2002]. This observed low velocity may be explained by the fact that there was no inertial interchange during the last 200 Myrs. Our value of 10 deg/Myr occurring after an 
inertial interchange is the speed limit for the model used in this study: $T_{R}$, the characteristic time of the delayed readjustment of the equatorial bulge of a rotating planet toward this fluid position, about 20 kyrs and inertia perturbations about $1-2 \times 10^{-5} I_{0}$ [Tsai and Stevenson, 2007].

Keeping in mind these orders of magnitude, we will now combine the "girdle" of subductions, Tethyan-like plate subductions, collisions and one or two antipodal domes, in two quite speculative but nevertheless interesting examples. First, we suggest that cusps observed in the TPW between $320 \mathrm{Ma}$ and the Present (one around $230 \mathrm{Ma}$ and the other one around $190 \mathrm{Ma}$ ) may result from earlier major geodynamic events. We then compute the TPW trigerred by the complex subduction history during the formation and the dislocation of the supercontinent Rodinia.

\section{Paleo Movement of Continents Since $\mathbf{3 0 0} \mathbf{~ M a}$ and Cusps in the TPW}

Let us now apply these simple examples to explain the TPW observed during the assembly and the destruction of the Pangea. In a previous paper [Greff-Lefftz and Besse, 2012], we have modeled the positions of the subduction zones and the surface velocities since $400 \mathrm{Myrs}$, based on geological and paleomagnetic reconstructions and constrained by subduction volcanism. To summarize, the peri-Pacific subductions are active for long period of times during the Paleozoic (Example 2) but parts of them are locally interrupted (Example 4) and over this period, there are episodical stop and rebirth of subductions (Example 1). The domes have been modeled as two antipodal domes in the bottom of the mantle and their positions and size constrained by intraplate volcanism at the surface. Using these two inputs, we have shown that, because there is no stop of the girdle of subduction, the minimum PIA remains relatively stable and close to an axis passing through the center of the ring of subduction and that the presence of the two antipodal domes at the base of the mantle reinforces this result. There is no inertial interchange since $300 \mathrm{Ma}$. The rotation axis remains consequently in a plane perpendicular to the domes axis, and we have found that, in this plane, a major trend of both observed and computed TPW are successive oscillatory tracks separated by abrupt cusps. Following the example 4, an important conclusion is that these cusps may not be synchronous with events such as the collision, but from a combination of events that happens earlier and which affects the inertia of Earth when the associated masses are in the deep mantle.

\section{Modelling True Polar Wander of a Real Supercontinent: Rodinia}

We investigate now the inertial interchanges and TPW induced by the formation and breakup of Rodinia, a supercontinent thought to have existed between 1100 and 720 million years ago [Dalziel, 1991]. Its configuration, formation or evolution are still highly controversial, and there are debates on the number of cratons, their relative configuration, and the exact timing of assembly and breakup [Hoffman, 1991; Weil et al.,1998; Torsvik, 2003, Meert and Torsvik, 2003, Li et al., 2008, Evans, 2009]. Amongst the last attempts to reconstruct Rodinia, a multidisciplinary research group [Li et al., 2008] has published paleogeographic maps that document the evolution and location of major crustal domains of the Precambrian continental blocks, and document also the subduction activity with respect to time. These maps were updated without major changes in a recent paper by Li et al. [2013]. Despite the large variability in the reconstructions, a robust feature is perhaps an episode of a global plate motion derived from paleomagnetic data, with a remarkable event between 800 and $780 \mathrm{Ma}$, bringing the center of the entire supercontinent from polar to equatorial latitudes in some tens of million years, and interpreted as an episode of True Polar Wander. This interpretation derives from an older scenario by Li et al. [2004] in which South China was located between Australia and Laurentia, and Rodinia broke apart by ca.750 Ma. Their analysis indicates some $60^{\circ}$ southward motion of South China by using their Xiaofeng dykes poles at $802 \pm 10 \mathrm{Ma}$ and the $748 \pm 12 \mathrm{Ma}$ Liantuo pole [Evans et al., 2000]. This analysis is then confirmed by the pole positions of the Indian Harohalli dykes at $814 \pm 34$ Ma [Radhakrishna and Mathew, 1996] compared with the 771-751 Ma Malani Igneous Suite [Torsvik et al., 2001], and a rotated pole from the 755-748 Ma Mahe dykes from Seychelles [Torsvik et al., 2001]; The Australian poles indicate the same evolution using the ca.820 Ma Wooltana Volcanics pole [McWilliams and McElhinny, 1980], the pole from the cap dolomite of the Walsh Tillite [Li, 2000], and the 755 \pm 3 Ma Mundine Well dykes pole [Wingate and Giddings, 2000]. Finally, they argue that these poles appear to be in agreement with the Congo poles at 795 \pm 7 Ma (Gagwe lavas) and the 755 25 Ma Mbozi Complex pole [Meert et al., 1995]. A quick polar wander episode was also found on Svalbard at around 800 Ma by Maloof et al. [2006]. 

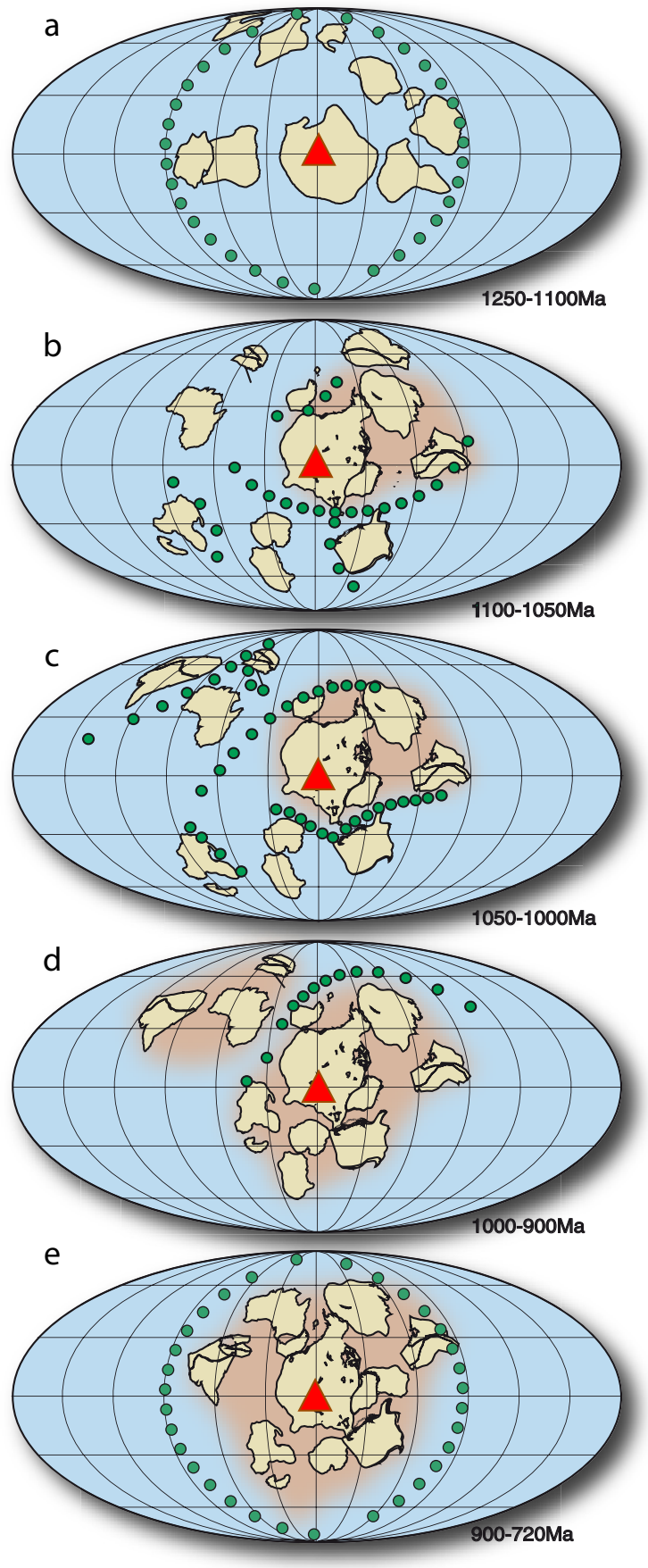

Figure 6. Interpolated reconstruction stages in the Laurentia fixed mantle reference frame. The relative positions between blocks and Laurentia are reconstructed from the maps of Pisarevsky et al. [2013] for the stage 1250-1100 Ma, and drawn using the Euler rotation poles of Li et al. [2008] for stages from 1100 to $720 \mathrm{Ma}$. Subductions (green circles) are from the same paper. Vergences of subductions are not drawn, since our model assumes that slabs sink vertically in the mantle. The red triangle is the center $C$ of the small circle surrounding the supercontinent.

through the whole mantle is about 127 Myr. Consequently, we have as initial condition for $t=1100 \mathrm{Ma}$, a stable distribution of mantle mass anomalies beneath all subduction zones from the surface down to the
Following Evans [2009], the resulting APW loop in the Laurentian path at c. 800 Ma is also supported by the data from other cratons that imply large APW shifts between 800 and $750 \mathrm{Ma}$ [ Li et al., 2004]. Although the reliability of $820-800 \mathrm{Ma}$ poles from Laurentia are uncertain during this period, the arguments brought by the listed above poles are sufficiently convincing to support if not ascertain TPW, and allows for the modeling of Rodinia motion from its formation to its breakup.

\subsection{Mantle Density Heterogeneities} To model the temporal evolution of mantle mass anomalies, we start with a mantle reference frame in which Laurentia is fixed (Figure 6). Indeed, Laurentia is a central plate during the assembly and destruction of Rodinia, a plate to which or from which most continents converged or diverged that stood as the "core" of the supercontinent. Here we use as the starting point the reconstruction of Li et al. [2008] at $1050 \mathrm{Ma}$.

Younger reconstructions (Figures 6b-6e) keep the 1050 Ma position of Laurentia, and the relative position of other landmasses are recomputed using the rotation parameters of Li et al. [2008]. The locations of subduction are those proposed in their set of maps.

During the time interval 1250-1100 Ma, little is known about the paleogeography, except for a 1.25 Ga paleomagnetic reconstruction of continents [Pesonen et al., 2003]. Very recent reconstructions by [Pisarevsky et al., 2013] indicate important landmasses divergences at 1380 and 1270 Ma following the major breakup of the Nuna supercontinent. We assume for this period that subduction proceeded with a constant velocity along a small circle with its center hereafter noted C: this girdle of subduction as well as the position of the continents derived by [Pisarevsky et al., 2013] are plotted in Figure 6a, in our Laurentia fixed reference frame. We set the velocity at $7.5 \mathrm{~cm} / \mathrm{yr}$, so that the characteristic time needed for the plate to sink 
CMB. To build our time-varying model of mantle density heterogeneities, we then use 4 plate stages interpolated from the reconstructions of [Li et al., 2008] at 1100-1050 Ma, 1050-1000 Ma, 1000-900 Ma and 900-720 Ma. The simplified shapes and locations of continents and subduction zones (green dots) in the fixed Laurentian reference frame are plotted in Figure 6. From 1100 to $900 \mathrm{Ma}$, the Rodinia supercontinent is on the way to aggregate, and the only mapped subductions are those that accommodate the convergence (Figures $6 \mathrm{~b}-6 \mathrm{~d}$ ): during the stages $1100-1000 \mathrm{Ma}$, the velocities of the plates are estimated to have been about $5 \mathrm{~cm} / \mathrm{yr}$, whereas for the 1000-900 Ma stage the velocity at the convergence zone between Australia-East Antarctica and the continent is smaller and is set at about $3 \mathrm{~cm} / \mathrm{yr}$. Rodinia is fully formed at $900 \mathrm{Ma}$ and a "subduction girdle" appears (Figure 6e), that wraps around all continents and predates the breakup of Rodinia: we model this girdle as subductions located on a small circle surrounding the supercontinent with a radius about $80^{\circ}$ and a constant velocity about $7.5 \mathrm{~cm} / \mathrm{yr}$. With this simple plate model, we compute the temporal evolution of the downwelling mantle mass anomalies from $1100 \mathrm{Ma}$ onward. The temporal evolution of the associated inertia tensor perturbations is plotted on Figure 7a.

For the upwelling mass anomalies, we extend the simple model described in the previous section: one or two thermo-chemical domes that are chemically denser than the overlying mantle, explaining their stability over long periods of time, and that are probably overlain by hot and less dense large-scale upwellings or plumes in the ambient mantle, which may dominate the effect on the geoid. We assume the existence of two antipodal domes for the time intervals (1250-1000 Ma and 800-720 Ma) during which the girdle of subducted slab has reached the bottom of the mantle, the time intervals of divergence (1250-1100 Ma and 900-720 Ma) delayed by $100 \mathrm{Myr}$, the duration of slab preclusion required to generate an upwelling under a mature supercontinent [Evans, 1998]. During the time interval of convergence (1100-900 Ma) also delayed by 100 Myrs (1000-800 Ma), we suppose one single dome. For simplicity we assume the domes to be stable with time over these intervals. We present in Figure $7 \mathrm{~b}$ the temporal evolution of the associated inertia tensor perturbations.

\subsection{Polar Motion}

Solving the equation (7), we compute the temporal evolution of the latitude and of the longitude of the pole of rotation as well as its velocity (Figure 7c). For our simple modelization with a small circle of subduction (Figure 6a), at $t=1100 \mathrm{Ma}$ the maximum PIA could be anywhere in the plane perpendicular to the the axis passing through the center of the continent. But we assume that at $t=1100 \mathrm{Ma}$, the pole of rotation was at the North pole. This is indicated by the paleo-reconstructions of Li et al. [2008] in the paleomagnetic reference frame, a frame in which the axis of rotation coincides with the North pole. We plot, on an orthographic projection, the polar wander between 1100 and $720 \mathrm{Ma}$ in the center of Figure 8 (black line) in the Laurentia fixed mantle reference frame.

At $1100 \mathrm{Ma}$, because of the symmetry of the girdle of subduction zones (Figure 8a), the minimum PIA coincides with the axis $O C$, whereas the intermediate and maximum PIAs are in a plane noted $P$ (Figure 8, red great circle) perpendicular to this axis OC. The "subduction girdle" stops at $t=1100 \mathrm{Ma}$, but the internal masses associated with the previous/ancient subducted plates, continue to sink toward the CMB (Figure $8 b)$, maintaining the rotational axis in the plane $P$. This stabilization is enhanced by the presence of equatorial domes during this interval. Consequently, smaller plates sinking during stages 1100-1050, 1050-1000, and 1000-900 Ma lead to smaller perturbations of inertia tensors and consequently produce only cusps in the polar motion, which remains in plane $P$. With our initial condition (pole at the North pole at $t=1100$ $\mathrm{Ma}$ ), we obtain one cusp around 1050 toward East, motion with very small amplitude (Figure 7c) followed by a large drift in polar motion toward the equator, still in the plane $P$, until $900 \mathrm{Ma}$. At $t=900 \mathrm{Ma}$, there is no more influence of the previous "subduction girdle," and the maximum PIA is related to the geometrical distribution of the subducted plates (Figure 8c) and to the domes, i.e., close to the equator. At that time, a new "subduction girdle" forms around the continents (Figure 8d), producing a large perturbation of the inertia tensor. During the next 75 Myrs, the rotation axis drift toward the center of Laurentia, the new maximum PIA. This is followed by an episode of inertial interchange (IITPW), at $t=825 \mathrm{Ma}$, and the minimum PIA returns to the center of Laurentia, whereas the rotational pole returns to its initial position (i.e., the North pole of our Laurentia-fixed reference frame).

These results show that the subducted plates within the mantle are able to trigger the major TPW episodes observed by paleomagnetism. We are aware of the uncertainties in our model, but a robust result appears: 
(a)

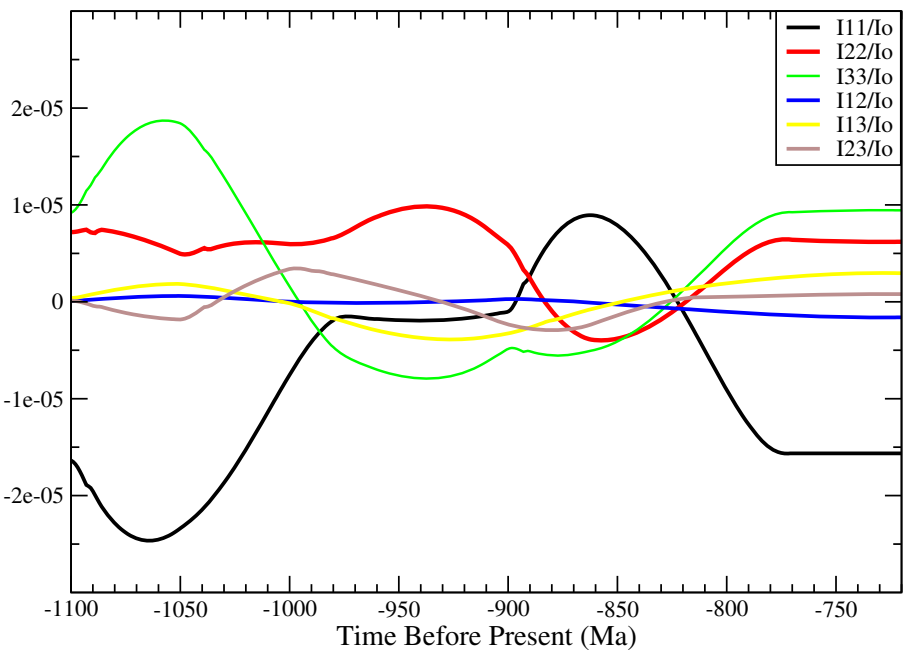

(b)

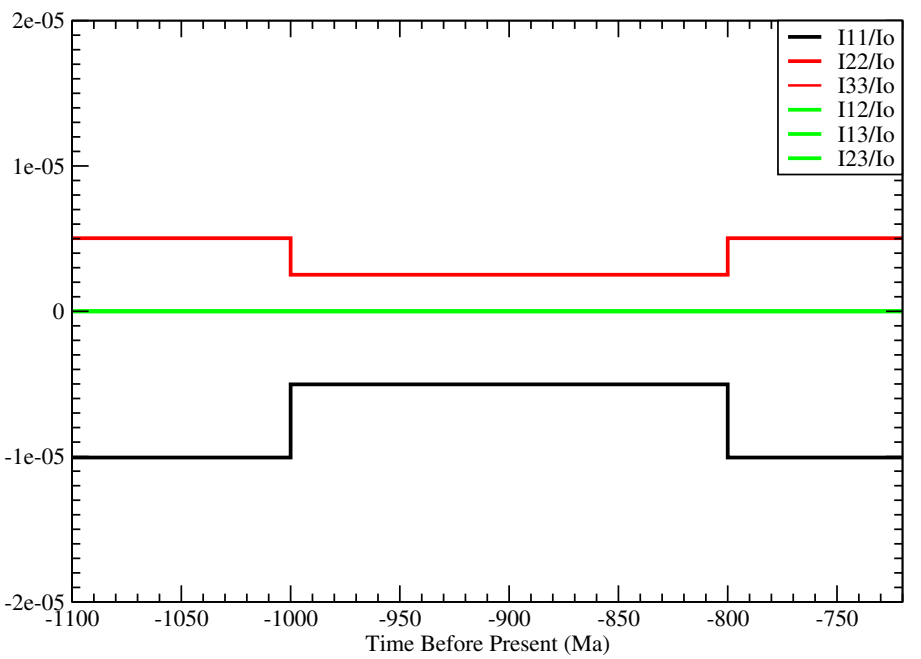

(c)
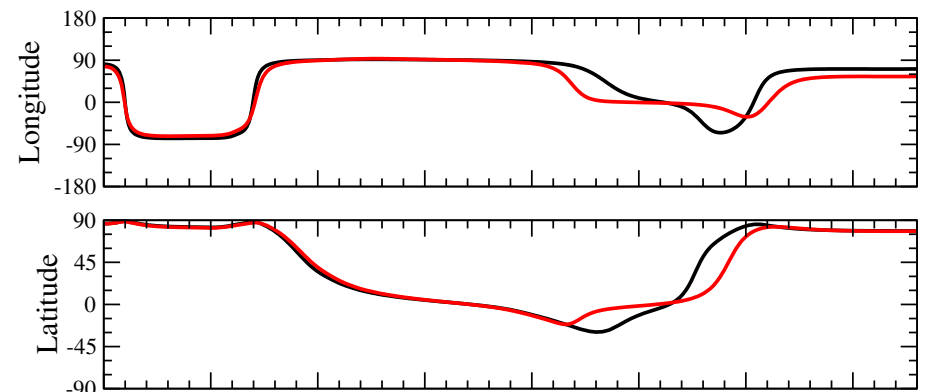

Figure 7. (a) Temporal evolution of the inertia tensor perturbations induced by the downwelling cold slabs. (b) Temporal evolution of the inertia tensor perturbations induced by the domes. (c) Temporal evolution of the latitude and longitude of the associated polar motion and its velocity: in black line when we take into account both the sinking plates and the domes and in red line when we take into account the plates alone. 
a)

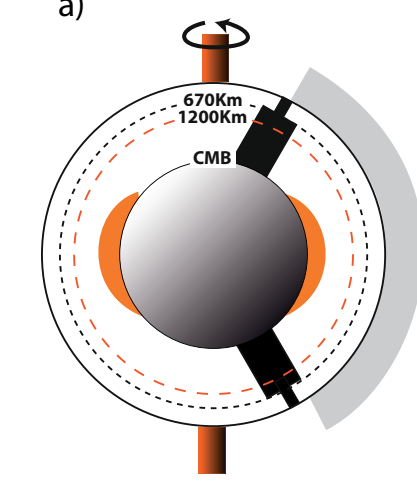

b)

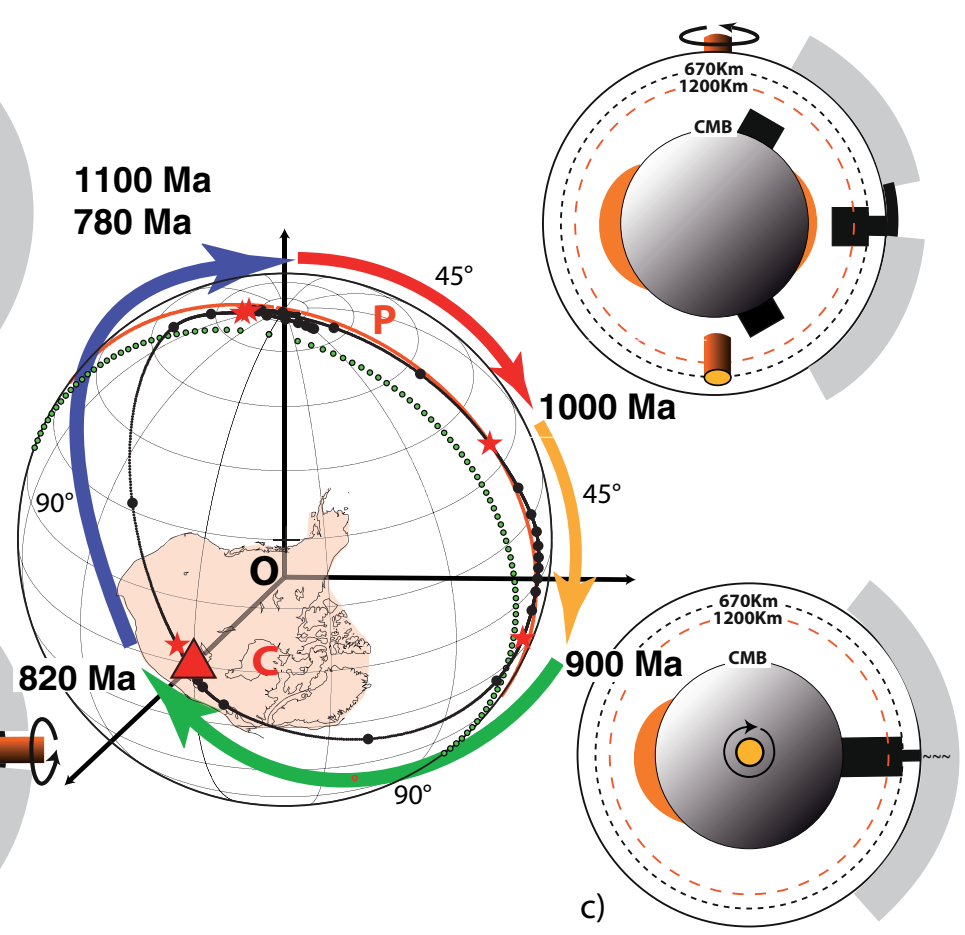

d)

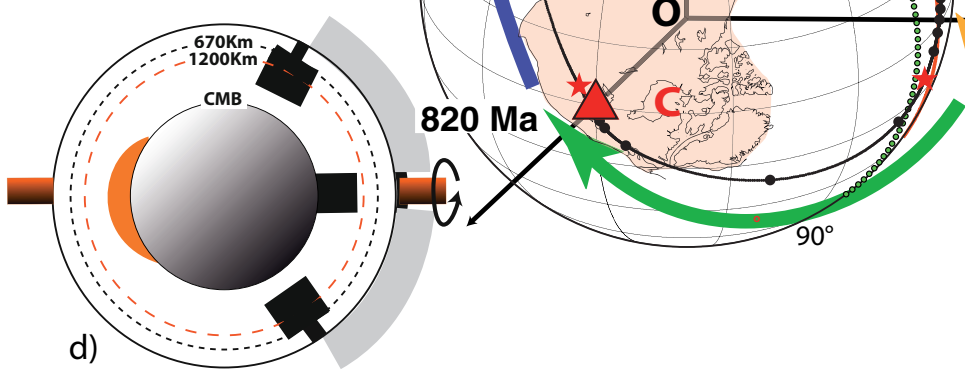

Figure 8. (middle) Time evolution of our modeled rotation axis with respect to Laurentia (light pink). Red stars are the pole positions for the ages discussed in the text, black dots the pole position every 10 Myr. The trajectory is figured as the thin black line. The green small circle is the trace of the "subduction girdle" with the red triangle at its center $C$. The red great circle defines the P plane perpendicular to the OC axis (see text). (periphery) mantle mass anomalies for the ages discussed in the text ((a) $1100 \mathrm{Ma}$ and $780 \mathrm{Ma}$, (b) $1000 \mathrm{Ma}$, (c) 900 $\mathrm{Ma}$, and (d) $820 \mathrm{Ma}$ ), subducted slabs are figured in black, domes in orange and continents in grey; thick orange axis shows schematically the position of the rotational axis.

the necessary and sufficient condition to have an episode of IITPW is that the pole of rotation has to be in a plane perpendicular to the axis passing through the center of the continent, when the girdle of subduction restarts.

\subsection{Comparison to the Observed True Polar Wander}

In order to confront our results with available paleogeographic reconstructions, we use our computed rotational pole to rotate our Laurentia fixed reference in such a way that the rotation axis intersects the Earth's surface at the North pole. This reference frame is directly comparable with the paleomagnetic reference frame. The modeled positions of the subduction zones and of the continents are plotted in the Figure 9 (right column) for different times windows. For $t=1050 \mathrm{Ma}$, continents are located symmetrically with respect to the equator and $C$ lies at the origin $[0,0]$. Then all continents are rotating counterclockwise by about $45^{\circ}$ from 1050 to $1000 \mathrm{Ma}$, and then by another $45^{\circ}$ from 1000 to $900 \mathrm{Ma}$. However, let us recall that the amplitudes of the E/W rotations are strongly dependent on the initial position of the pole in the plane $P$ at $t=1000 \mathrm{Ma}$.

At $t=900 \mathrm{Ma}$, the new "subduction" around the continents starts, and because of the inertial interchange described above all of the continents drift toward the North pole. 75 Myrs later, the minimum PIA is again centered on Laurentia and the supercontinent is centered on the equator.

To compare our modeled motion, in direction and amplitude with the observed paleomagnetic motion described in Li et al. [2008], we try to separate plate tectonics from true polar wander in Li's reconstruction by computing the small circle which best fits the envelope of continents using the PaleoMac Software Package [Cogné, 2003], and analyze first the rotations, and then the latitudinal motion of the small circle center (Figure 9, left column). The $45^{\circ}$ counter clockwise (CCW) rotation determined between 1.05 and $1 \mathrm{Ga}$ by the model (Figure 9, right) is not observed on the corresponding reconstruction, but the $1 \mathrm{Ga}$ to $900 \mathrm{Ma} 45^{\circ}$ 


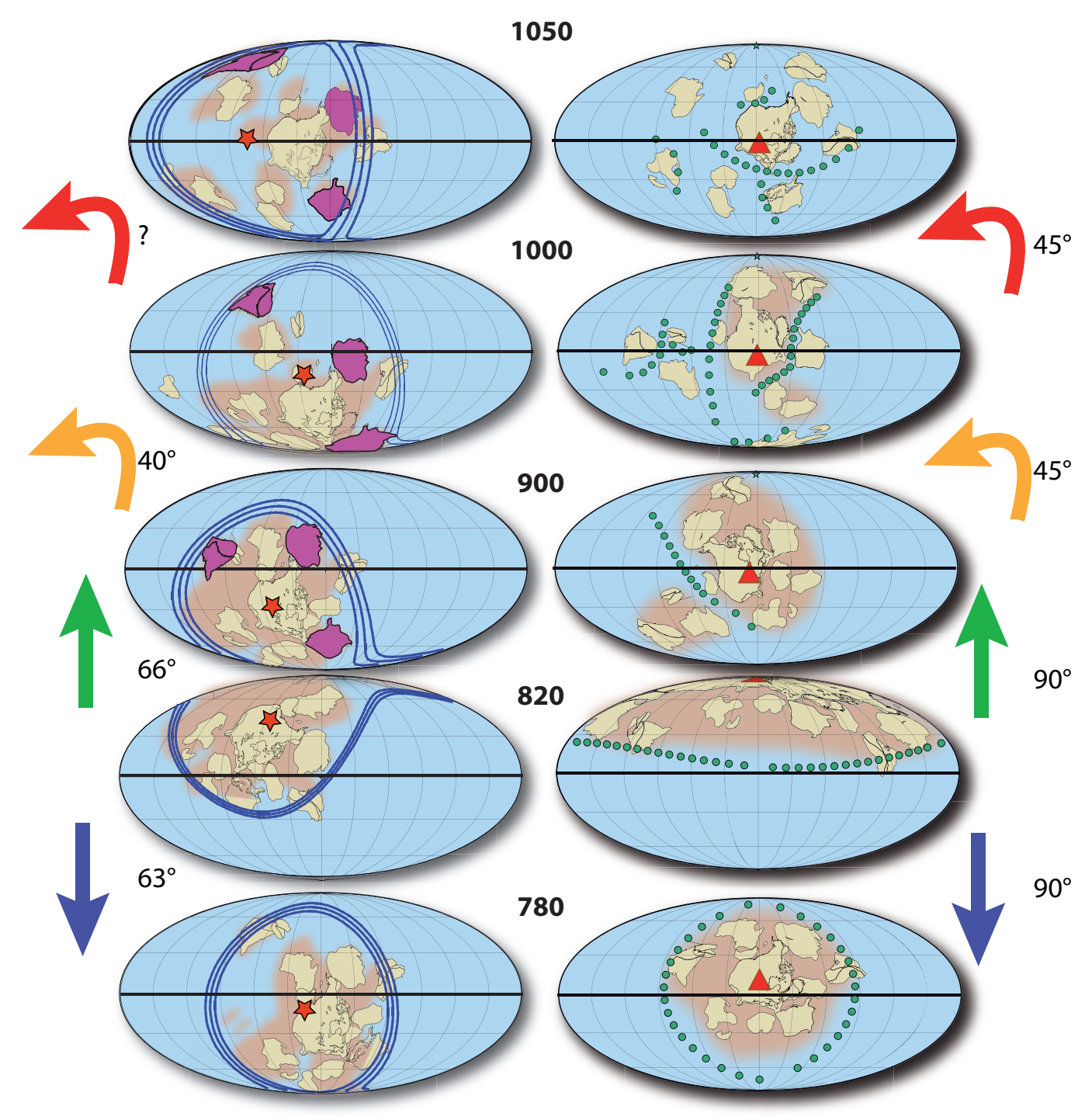

Figure 9. Comparison between paleogeographic maps of (left) Li et al. [2008] and (right) our model in the paleomagnetic reference frame. Arrows, motion inferred in each case; Blue circles, best fit of continent envelopes (with $95 \%$ error bar) determined using the PaleoMac Software [Cogné, 2003]. Red Stars, centers of the small circles; India, Siberia and Baltica are filled in purple for a better visualization of rotations. Red Triangles, center of Laurentia; Subduction zones, green circles; Ages are in million years.

CCW rotation predicted by the model seems to compare with a $40^{\circ}$ observed rotation despite some uncertainties.

The other polar wander events correspond well for the younger time windows: the $90^{\circ}$ poleward motion between 900 and 820 Ma predicted by the model compares well with a $66^{\circ}$ observed rotation, followed by the modeled $90^{\circ}$ equatorward motion between 820 and 780 Ma roughly similar to the $63^{\circ}$ observed one.

The agreement not only between directions, but also between amplitudes of motion in the model and the plate tectonic reconstructions [Li et al., 2008] appears thus good. We however recall the readers that Rodinia configuration is strongly debated.

\section{Discussion and Conclusion}

In this paper, we use a geodynamic model in which the temporal evolution of the mantle mass anomalies are computed using plate reconstructions and geologic maps. We assume that subducted slabs sink 
vertically into the mantle down to the $\mathrm{CMB}$, with a velocity reduction and a thickening with a 4 factor within the lower mantle. We also take into account large-scale domes in the lower mantle and show that, for certain configurations, subductions clearly dominate the triggering of TPW events. This result is thus in contradiction with models that favor Superplumes as the main mechanism that triggers TPW, such as for example those derived from convection models [Zhong et al., 2007; Li and Zhong, 2009]. Looking closely, the difference is due to the amount of subduction present in the mantle. In the numerical approach, some fine filaments of cold materials essentially represent the downwelling around the supercontinent whereas in our approach, large sheets of cold material are sinking down to the lower mantle and thus dominate the inertia. Numerical models are probably unable to reproduce what is currently observed by seismic tomography: the precise amount of cold slabs in the lower mantle. However our results are in good agreement with a recent paper by Steinberger and Torsvik [2010] who explained essential features of TPW for the last 300 Myrs as caused by changes in mantle density anomalies due to subduction, while density anomalies related to LLSVPs, remaining largely unchanged, stabilized the planet.

From plate reconstructions and our model, two end member configurations emerge:

1. Continents are mainly located in a single E-W hemisphere, more or less symmetrical with respect to the equator, and a girdle of subductions is active all around: this is the case at present (circum-Pacific subductions), and this situation may have lasted since at least 250 Ma or even more [Torsvik et al., 2008; Zhang et al., 2010; Rouby et al., 2010]. This is also the case for the 1050-900 Ma time interval--during which the subduction girdle has stopped but is still active in the lower mantle--and a long period after $780 \mathrm{Ma}$ in our study (see Figure 9). This configuration is driven by dominant long lived active subductions zones around continents reaching a sufficient depth in the lower mantle to stabilize the Earth rotation pole in a plane perpendicular to an axis passing through the Earth's center of mass $O$ and the center of the girdle $C$, an effect reinforced by the presence of one or two domes at the bottom of the mantle. The present state of convection as seen by seismic tomography leads to same conclusions with a degree 2 signal characterized by two antipodal regions of low velocities, more or less centered on the equator and separated by a circum-polar torus of high velocities material attributed to subductions, in which lies the rotational pole [Dziewonski et al., 2010]. During these periods, oscillatory polar wander is attributed to TPW around the minimum inertial axis [Evans, 2003], situated close to the center of the supercontinent, and the cusps observed in the TPW may not result from synchronous events such as a collision, but from a combination of events happening earlier which affects the inertia of Earth when the associated slabs are in the deep mantle.

2. Continents leave their "stable" positions and drift more or less toward a N-S Hemisphere. This is the case at $820 \mathrm{Ma}$ in Li's reconstructions, and some other periods in the Earth history. This situation would result with a lack or a diminution of subductions girdle at the periphery of continents, during a time interval lasting a few tens of millions of years, followed by a renewed ring of subduction. During this time interval, other subductions such as those situated between continents (see Figure 9) may have a dominant effect. When the girdle of subduction, centered on the equator, restarts, there will be global motion of the supercontinent toward the pole, followed by an equatorward motion, when most of the masses associated with the girdle of subductions are in the lower part of the mantle. A new stable state is then reached when a sufficient amount of material in the lower mantle stabilizes again the Earth rotation pole in a plane perpendicular to an axis passing through $O$ and the center of the girdle.

TPW may thus be sometimes driven by episodic subductions during the Wilson cycle: alternating fast subduction girdles around continents during the divergence phases, and both reduced or stopped subductions activity around continents, with moderate inter-continental subductions during convergence phases, would explain respectively the observed global rotation with respect to a pole located at the center of the supercontinent and the large poleward/equatorward motions.

The input data of our model (interpolated reconstruction stages in the Laurentia fixed mantle reference frame) have been drawn using the Euler rotation poles of [Li et al., 2008]. We thank Y. Ricard for giving us his geodynamic model. We are also grateful to B. Steinberger and an anonymous reviewer for their helpful comments on our manuscript. This study was supported by CNRS-INSU (SYSTER) and is IPGP contribution 3587.

\section{References}

Cambiotti, G., Y. Ricard, and R. Sabadini (2011), New insights into mantle convection true polar wander and rotational bulge readjustment, Earth Planet. Sci. Lett., 310, 538-543.

Chan, N. H., J. X. Mitrovica, I. Matsuyama, J. R. Creveling, and S. Stanley (2011), The rotational stability of a convecting earth: Assessing inferences of rapid TPW in the late cretaceous, J. Geophys. Int., 187(3), 1319-1333.

Cogné, J.-P. (2003), PaleoMac: A Macintosh ${ }^{\mathrm{TM}}$ application for treating paleomagnetic data and making plate reconstructions, Geochem. Geophys. Geosyst., 4(1), 1007, doi:10.1029/2001GC000227.

Collins, W. J. (2003), Slab pull, mantle convection, and Pangaean assembly and dispersal, Earth Planet. Sci. Lett., 205, $225-237$. 
Dalziel, I. W. D. (1991), Pacific margins of Laurentia and East Antarctica-Australia as a conjugate rift pair: Evidence and implications for an Eocambrian supercontinent, Geology, 19(6), 598-601.

Dziewonski, A. M. (1984), Mapping the lower mantle: Determination of lateral heterogeneity in P velocity up to degree and order 6, J. Geophys. Res., 89, 5929-5952, doi:10.1029/JB089iB07p05929.

Dziewonski, A. M., V. Lekic and B. A. Romanowicz (2010), Mantle anchor structure: An argument for bottom up tectonics, Earth Planet. Sci. Lett., 299, 69-79.

Evans, D. A. D. (1998), True Polar Wander, a supercontinental legacy, Earth Planet. Sci. Lett., 157, 1-8.

Evans, D. A. D. (2003), True polar wander and supercontinents, Tectonophysics, 362, 303-320.

Evans, D. A. D. (2009), The palaeomagnetically viable, long-lived and all-inclusive Rodinia supercontinent reconstruction, Geol. Soc. Spec. Publ., 327, 371-404.

Evans, D. A. D., Z. X. Li, J. L. Kirschvink, and M. T. D. Wingate (2000), A high-quality mid-Neoproterozoic paleomagnetic pole from South China, with implications for ice ages, regional stratigraphy, and the breakup configuration of Rodinia, Precambrian Res., 100, $313-334$. Gold, T. (1955), Instability of the Earth's axis of rotation, Nature, 175(4456), 526-529.

Goldreich, P., and A. Toomre (1969), Some remarks on polar wandering, J. Geophys. Res., 74, 2555-2567.

Greff-Lefftz, M. (2004), Upwelling plumes, superswells and true polar wander, Geophys. J. Int. 159, 1125-1137.

Greff-Lefftz, M. (2011), Length of day variations due to mantle dynamics at geological timescale, J. Geophys. J. Int., 187, $595-612$.

Greff-Lefftz, M., and J. Besse (2012), Paleo movement of continents since 300 Ma, mantle dynamics and large wander of the rotational pole, Earth Planet. Sci. Lett., 345, 151-158.

Hoffman, P. F. (1991), Did the break-out of Laurentia turn Gondwanaland inside-out, Science, 252, 1409-1412.

Li, Z. X. (2000), New palaeomagnetic results from the 'cap dolomite' of the Neoproterozoic Walsh Tillite, northwestern Australia, Precambrian Res., 100, 359-370.

Li, Z. X., and S. J. Zhong (2009), Supercontinent-superplume coupling, true polar wander and plume mobility: Plate dominance in wholemantle tectonics, Phys. Earth Planet. Int., 176, 143-156.

Li, Z. X., D. A. D. Evans, and S. Zhang (2004), A $90^{\circ}$ spin on Rodinia: Possible causal links between the Neoproterozoic supercontinent, superplume, true polar wander and low-latitude glaciation, Earth Planet. Sci. Lett., 220, 409-421.

Li, Z. X., et al. (2008), Assembly configuration and break-up history of Rodinia: A synthesis, Precambrian Res., 160, $179-210$.

Li, Z. X., D. A. Evans, and G. P. Halverson (2013), Neoproterozoic glaciations in a revised global palaeogeography from the breakup of Rodinia to the assembly of Gondwanaland, Sediment. Geol., 294, 219-232.

Lithgow-Bertelloni, C., and M. Richards (1998), The dynamics of cenozoic and mesozoic plate motions, Rev. Geophys., 36, 27-78.

Maloof, A. C., G. P. Halverson, J. L. Kirschvink, D. P. Schrag, B. P. Weiss and P. F Hoffman (2006), Combined paleomagnetic, isotopic, and stratigraphic evidence for true polar wander from the Neoproterozoic Akademikerbreen Group, Svalbard, Norway, GSA Bull., 118(9/10), 1099-1124.

McNamara, A., and S. Zhong (2005), Thermochemical structures beneath Africa and the Pacific Ocean, Nature, 437, 1136-1139, doi: 10.1038/nature04066

McWilliams, M. O., and M. W. McElhinny (1980), Late Precambrian paleomagnetism of Australia: The Adelaide Geosyncline, J. Geol., 88, $1-$ 26.

Meert, J. G., and T. H. Torsvik (2003), The making and unmaking of a supercontinent: Rodinia revisited, Tectonophysics, 375, $261-288$.

Meert, J. G., R. Van der Voo, and S. Ayub (1995), Paleomagnetic investigation of the Neoproterozoic Gagwe lavas and Mbozi Complex, Tanzania and the assembly of Gondwana, Precambrian Res., 74, 225-244.

Munk, W. H., and G. J. F. MacDonald (1960), The Rotation of the Earth, Cambridge monograph on mechanics and applied mathematics, 323 pp., Cambridge Univ. Press, U. K.

Pesonen, L. J. S.-A. Elming, S. Mertanen, S. Pisarevsky, M. S. DAgrella-Filho, J. G. Meert, P. W. Schmidt, N. Abrahamsen, and G. Bylund (2003), Palaeomagnetic configuration of Supercontinents during the Proterozoic, Tectonophysics, 375, 289-324.

Pisarevsky, S. A., S.-A. Elming, L. J. Pesonen, and Z.-X. Li (2013), Mesoproterozoic paleogeography: Supercontinent and beyong, Precambrian Res., 244, 192-206.

Radhakrishna, T., and J. Mathew (1996), Late Precambrian (850-800 Ma) palaeomagnetic pole for the south Indian shield from the Harohalli alkaline dykes: Geotectonic implications for Gondwana reconstructions, Precambrian Res., 80, 77-87.

Ricard, Y., M. Richards, C. Lithgow-Bertelloni, and Y. Le Stunff (1993a), A geodynamic model of mantle density heterogeneity, J. Geophys. Res., 98(B12), 21,895-21,909.

Ricard, Y., G. Spada, and R. Sabadini (1993b), Polar Wandering of a dynamic Earth, Geophys. J. Int., 113, 284-298.

Richards, M. A., and B. Hager (1984), Geoid anomalies in a dynamic Earth, J. Geophys. Res., 89, 5987-6002.

Richards, M. A., Y. Ricard, C. Lithgow-Bertelloni, G. Spada, and R. Sabadini (1997), An explanation for Earth's long-term rotational stability, Science, 275, 372-375.

Rouby, H., M. Greff-Lefftz, and J. Besse (2010), Mantle dynamics, geoid, inertia and TPW since 120 Ma, Earth Planet. Sci. Lett., 292(3-4), 301311.

Steinberger, B., and R. J. O'Connell (1997), Changes of the Earth's rotation axis owing to advection of mantle density heterogeneities, Nature, 387, 169-173.

Steinberger, B., and T. H. Torsvik (2010), Toward an explanation for the present and past locations of the poles, Geochem. Geophys. Geosyst., 11, Q06W06, doi:10.1029/2009GC002889.

Steinberger, B., and T. H. Torsvik (2012), A geodynamic model of plumes from the margins of Large Low Shear Velocity Provinces, Geochem. Geophys. Geosyst., 13, Q01W09, doi:10.1029/2011GC003808.

Torsvik, T. H. (2003), The Rodinia Jigsaw Puzzle, Science, 300, 1379-1381.

Torsvik, T. H., L. M. Carter, L. D. Ashwal, S. K. Bhushan, M. K. Pandit, and B. Jamtveit (2001a), Rodinia redefened or obscured: Palaeomagnetism of the Malani Igneous Suite (NW India), Precambrian Res., 108, 319-333.

Torsvik, T. H., L. D. Ashwal, R. D. Tucker, and E. A. Eide (2001b), Neoproterozoic geochronology and palaeogeography of the Seychelles microcontinent: The India link, Precambrian Res., 110, 47-59.

Torsvik, T. H., M. A. Smethurst, K. Burke, and B. Steinberger (2008), A long term stability in deep mantle structure: Evidence from the 300 Ma Skagerrak-Centered Large Igneous Province (the SCLIP), Earth Planet. Sci. Lett., 267, 444-452.

Tsai, V. C., and D. J. Stevenson (2007), Theoretical constraints on true polar wander, J. Geophys. Res., 112, B05415, doi:10.1029/ 2005JB003923.

Weil, A. B., R. Van der Voo, C. Mac Niocaill, and J. G. Meert (1998), The Proterozoic supercontinent Rodinia: Paleomagnetically derived reconstructions for 1100 to 800 Ma, Earth Planet. Sci. Lett., 154, 13-24. 
Wingate, M. T. D., and J. W. Giddings (2000), Age and palaeomagnetism of the Mundine Well dyke swarm, Western Australia: Implications for an Australia-Laurentia connection at 755 Ma, Precambrian Res., 100, 335-357.

Yoshida, M., and M. Santosh (2011), Supercontinents, mantle dynamics and plate tectonics: A perspective based on conceptual vs. numerical models, Earth Sci. Rev., 105, 1-24.

Zhang, N., S. Zhong, W. Leng, and Z. X. Li (2010), A model for the evolution of the Earth's mantle structure since the Early Paleozoic, J. Geophys. Res., 115, 1-22.

Zhong, S. J., N. Zhang, Z. X. Li, and J. H. Roberts (2007), Supercontinent cycles, true polar wander, and very long-wavelength mantle convection, Earth Planet. Sci. Lett., 261, 551-564. 